\title{
Fitting single-cell models to voltage- and current-clamp data: Bayesian filtering
}

\author{
Sean G Carver*, Michael L Hines \\ From Nineteenth Annual Computational Neuroscience Meeting: CNS*2010 \\ San Antonio, TX, USA. 24-30 July 2010
}

We have incorporated into the NEURON simulation environment parameter estimation by maximizing the log-likelihood function. For linear models, we use an optimal Bayesian filter, the Kalman filter [1], to compute the log-likelihood. For non-linear models, likelihood cannot be computed exactly and we have explored several approximate Bayesian filters including an extended Kalman filter [1] and a particle filter [1].

Bayesian filtering iteratively implements two steps for each data point: prediction and update. The first step uses the model to predict the state of the cell at the next time data is collected. The second step updates the prediction based on the new data point. Even when the model is deterministic, both the "predicted state" and the "updated state" are actually joint distributions for all components of state, even hidden components that are not measured. To give a deterministic model a probabilistic structure, we add Gaussian white noise to one or more of its states. The update step implements Bayes Rule to force the model to better follow the data. Bayes rule selects the optimal tradeoff between measurement noise and process noise. It is assumed by the method that it is actually the noise that forces the model; the log-likelihoods of the required noise are tallied. A graphical interface allows the user to obtain an intuitive understanding of how the standard deviations of the state estimates propagate and are modified by Bayes rule forcing the model to follow the data.

The likelihood can be used to generate $95 \%$ confidence regions for the parameters using the chi-squared statistic [2]. We test the validity of this construction using simulated data where $95 \%$ of the confidence regions drawn should cover the true values of the parameters. We similarly test the validity of our confidence

\footnotetext{
* Correspondence: sean.carver@yale.edu

Neurobiology Department, Yale University, New Haven, CT 06520, USA
}

regions under the often inevitable situation that the model being fitted has been misspecified.

Finally we compare the log-likelihood objective function with the square norm objective function in terms of location of minima and the efficiency of search methods such as Praxis in finding the minima when starting from reasonable parameter values that are not close to their true value.

\section{Acknowledgments}

This work was supported by an NIH ARRA supplement to NS11613 and by $\mathrm{NIH}$ grant NS11613.

Published: 20 July 2010

\section{References}

1. Sarkka S, Tamminen T, Vehtari A, Lampinen J: Probabilistic methods in multiple target tracking: review and bibliography. Research report B36, Laboratory of Computational Engineering, Helsinky University of Technology, 951-22-6938-4 2004.

2. Meeker WQ, Escobar LA: Teaching about approximate confidence regions based on maximum likelihood. The American Statistician 1995, 49(1):48-53.

doi:10.1186/1471-2202-11-S1-P72

Cite this article as: Carver and Hines: Fitting single-cell models to voltage- and current-clamp data: Bayesian filtering. BMC Neuroscience 2010 11(Suppl 1):P72.

Submit your next manuscript to BioMed Central and take full advantage of:

- Convenient online submission

- Thorough peer review

- No space constraints or color figure charges

- Immediate publication on acceptance

- Inclusion in PubMed, CAS, Scopus and Google Scholar

- Research which is freely available for redistribution

Submit your manuscript at www.biomedcentral com/submit
C Biomed Central 